\title{
The Challenge of Changing to a Low-Carbon Economy: A Brief Overview
}

\author{
Jorge F. Carrasco1,2 \\ ${ }^{1}$ Dirección Meteorológica de Chile, Santiago, Chile \\ ${ }^{2}$ Universidad de Magallanes, Punta Arenas, Chile \\ Email: jorcar59@gmail.com
}

Received 8 December 2013; revised 8 January 2014; accepted 16 January 2014

Copyright (c) 2014 by author and Scientific Research Publishing Inc.

This work is licensed under the Creative Commons Attribution International License (CC BY). http://creativecommons.org/licenses/by/4.0/

(c) ()

\begin{abstract}
Climate change alters all sustainable development dimensions for a given nation or region, therefore, decreasing emission of GHG not only is an environmental issue, but also has implication on the economic, social and political matters. In 2009, the Copenhagen Accord adopted the $2^{\circ} \mathrm{C}$ global warming increase limit as an international policy, being this threshold of the maximum allowable warming to avoid dangerous and irreversible anthropogenic interference in the climate system. The observed monthly average $\mathrm{CO}_{2}$ concentrations in the atmosphere crossed the 400 parts per million thresholds, for the first time in April and May 2013. The energy sector is the single largest source of climate changing GHG emissions, and therefore moving from fossil fuel to clean energy production should be a priority challenge for all countries. For that, it is necessary to develop a low carbon economy for confronting the climate change.
\end{abstract}

\section{Keywords}

Climate Change; Carbon Dioxide; Low-Carbon Economy; $2^{\circ} \mathrm{C}$ Target

\section{Overview}

Since the release of the Fourth Assessment Report of the Intergovernmental Panel on Climate Change (IPCC) [1], when the main conclusion was that the climate change is unequivocal; the vast majority of the world reached the consensus that this environmental change is real and it is due to the atmosphere warming as a consequence of the increased concentration of greenhouse gases (GHG) of anthropogenic origin. This has recently been confirmed by the Fifth IPCC Report [2]. One of the main conclusions indicates that "human influence has been detected in warming of the atmosphere and the ocean, as well as, changes in the global water cycle, in reductions in snow and ice, in global mean sea level rise, and in changes in some climate extremes”. Also, the re- 
port reveals that "it is extremely likely (i.e., 95\% - 100\% probability) that human influence has been the dominant cause of the observed warming since the mid-20th century" [2]. Climate model simulations project further warming and changes in all components of the climate system as emissions of $\mathrm{CO}_{2}$ continue, or even if emissions of $\mathrm{CO}_{2}$ are stopped now [2]. Therefore, it is necessary to face and to be prepared for a warmer world than the present one, with an appropriate worldwide plan and/or with integrated and synergetic national programs that globally mitigate the emission of GHG. This mainly implies to end with our dependence on fossil fuels, which is the major source of carbon dioxide $\left(\mathrm{CO}_{2}\right)$ released into the atmosphere, and to assume that this action is a challenge that should be the main worldwide environmental problem of our time. The $\mathrm{CO}_{2}$ is the most important anthropogenic GHG contributing 64\% to the radiative forcing of the long-lived GHG, and it is responsible for $\sim 84 \%$ of the increment in radiative forcing since 2002 [3].

Climate change alters all sustainable development dimensions for a given nation or region, therefore, decreasing emission of GHG not only is an environmental issue, but also has implications on the economic, social and political matters. Since this issue was recognized by the global community, several actions and agreements have been taking place in the Conference of the Parties (COP) of the United Nations Framework Convention on Climate Change (UNFCCC). Among others, in 2009 the Copenhagen Accord endorsed the continuation of the Kyoto Protocol; it recognized that climate change is one of the greatest challenges of our time and emphasized the needed for a "strong political will to urgently combat climate change in accordance with the principle of common but differentiated responsibilities and respective capabilities". Also, it was recognized that deep cuts in global emissions are required according to science results [1] [2] and that countries should agree in cooperative way in stopping from rising global and national GHG emissions "as soon as possible". To achieve this, it is necessary to develop a low $\mathrm{CO}_{2}$ emission strategy in order to secure a sustainable development. Later in the COP at Durban 2011, the governments recognized the need of a new universal, legal agreement to deal with climate change beyond 2020, where all parties will play their part to the best of their ability. Meanwhile, an amendment to the Kyoto Protocol was adopted in the COP at Doha 2012 where the parties agreed on an 8-year second commitment period, in order to stabilize greenhouse gas concentrations in the atmosphere at a level that will prevent dangerous human interference with the climate system.

Also, the Copenhagen Accord adopted the $2^{\circ} \mathrm{C}$ global warming increase limit [4] as an international policy, being this threshold of the maximum allowable warming to avoid dangerous and irreversible anthropogenic interference in the climate, beyond this threshold the risks of significant damage to ecosystems and of non-linear responses are expected to increase rapidly. These actions are now even more urgent after knowing the results of the last Fifth IPCC Report [2]. The International Energy Agency (IEA) [4] also recognized that the energy sector is the single largest source of climate changing GHG emissions, and therefore changing from fossil fuel to clean energy production should be a priority challenge. This means developing an economy based on a low-emission pathway, in other words, establishing a low carbon economy (LCE) for confronting the climate change. This implies a low-fossil-fuel economy, or a decarbonized economy that has a minimal output of GHG emissions into the atmosphere, specifically $\mathrm{CO}_{2}$ as a result of human activity.

The IEA [5] recently indicated that even though Governments have decided collectively that the world needs to limit the average global temperature increase to no more than $2^{\circ} \mathrm{C}$ (as sooner as possible), any resulting global agreement related with this challenge will emerge after 2015 and new legal obligations will most probably begin after 2020. Meanwhile, despite the agreement taken by governments and that many countries are taking new actions, the GHG emission continues increasing and the world target for accomplishing the $2^{\circ} \mathrm{C}$ is drifting further from the track that it needed to follow [5]. In fact, the observed monthly average $\mathrm{CO}_{2}$ concentrations in the atmosphere crossed the 400 parts per million thresholds, for the first time in April and May 2013, in several observing stations (Barrow/Alaska-USA, Alert/Canada, Ny-Ålesund/Norway, Izaña/Canary Islands-Spain, and Mauna Loa/Hawaii-USA) [6]. Recently, the PwC (PricewaterhouseCooper LLP) [7] revealed that the annual rate reduction of $\mathrm{CO}_{2}$ emission for the 2012-2050 period, needed to accomplish the $2^{\circ} \mathrm{C}$ warming target, has risen from $3.7 \%$ to $5.1 \%$ (Figure 1) [6]. Also, the IEA indicated in its World Energy Outlook Special Report [5] that we are more likely to increase the air temperature between $3.6^{\circ} \mathrm{C}$ and $5.3^{\circ} \mathrm{C}$ during the 21th century, compared with pre-industrial values (see also Peter et al. [8]). Figure 1 also shows that the business as usual projection will not accomplish the $2^{\circ} \mathrm{C}$ target reduction. Neither will it be if the annual reduction rate is $3.7 \%$ as originally was estimated. If we continue the business as usual pathway, every year the annual reduction rate needed will be larger and therefore more challenge to achieve. Peter et al. [8] comparing the observed annual global $\mathrm{CO}_{2}$ emission with those projected by different IPCC scenarios, since the first report until those used in the fifth one, concluded that the current trend follows or even is above the worse scenario. They concluded that if the $\mathrm{CO}_{2}$ 


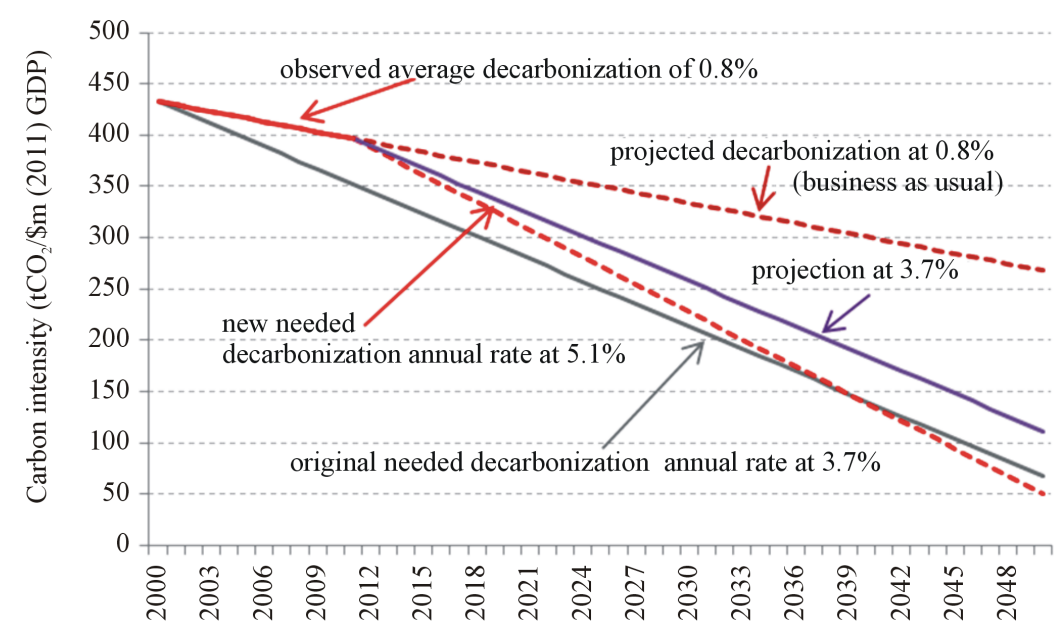

Figure 1. Linear rate of the global carbon intensity (decarbonization) expected for 2050, based on the PwC’s Low Carbon Economy Index-Global (Figure 1) [6].

emission track continues the global warming will be above the $2^{\circ} \mathrm{C}$ target, and that to return to the $2^{\circ} \mathrm{C}$ pathway requires a sustainable global mitigation, including capture and storage $\mathrm{CO}_{2}$, but also high level of technological, social and political innovations [8].

Despite of this, the $2^{\circ} \mathrm{C}$ target is still a feasible challenge but it is now more difficult to achieve and actions are urgently needed before 2020. It is well recognized that energy accounts for around two-thirds of GHG emissions, as more than $80 \%$ of global energy consumption is based on fossil fuels. Therefore, achieving a LCE is a worldwide challenge in order that the climate change impacts can be mitigated any time soon. Such an endeavor must be undertaken, not only by developed countries (Annex 1 of the Kioto Protocol), but it should also be a compromise by developing countries (non Annex 1 of the Kioto Protocol). However, any action should be in accordance with the principle of common but differentiated responsibilities and respective capabilities.

Natural energy resources are vital for securing economic growth and development for all countries, not just today but for future generations. The relationship between economic growth and the environment is complex. Changes in technology due to LCE can have the potential of reducing the environmental impacts, but also of affecting the economic growth. Traditional economy is based mainly on energy generated by using fossil fuel. For this reason many economical indexes include results of consumption of fossil fuel, like the economic growth, nation and people prosperity, and other overall cost and benefits. The LCE implies the development of a new way of generating energy, which should be based on "clean-renewable" sources. For the vast majority of the countries this shift is highly costly and it will affect their economy, mainly to those less-developed communities.

As indicated earlier, the international community recognizes that the climate change (and its impacts) is one of the largest problems facing humanity. This is well assumed in economic terms, but the challenge goes beyond this, arising ethical questions that many time are often overlooked, questions that have to be with ourselves and with our interaction with the environment including the ecosystems and the biodiversity. What should be the objectives of climate change, and who should bear the burdens of climate change? Who should be included in decision-making about mitigation and adaptation strategies? Is it only governmental decision? What role does the private sector play? Beinhocker and Oppenheim [9] indicated that moving to a LCE involving a technology shift might cause job losses in some sectors, but on the other hand is likely to create more jobs than it will destroy. Also, greater social equity could be an additional benefit of such a low-carbon revolution. For example, in developing countries innovations in power generation technology could make electricity both more affordable and more accessible to less-developed communities. Increased electrification has a wide variety of development benefits ranging from improved healthcare and access to clean water, to greater economic growth. Even, the development of a truly sustainable biofuels industry could offer vast economic opportunities for the rural poor communities.

Clearly climate change will impact our way of life, moving to a LCE for accomplishing the goal of $2^{\circ} \mathrm{C}$ target will cause changes in the current social status, on the people's capacity to enjoy fundamental rights to life, food, water and health [9]. This means that the $2^{\circ} \mathrm{C}$ target is likely to be too high to safeguard these rights. Then, we as 
worldwide society are able to confront the challenge imposed by climate change, in moving to a LCE and adopting polices for mitigation and adaptation, without compromising people's rights for a better life and the environment as a whole. No doubt that LCE requires an ethical and political framework that differs from current ones.

Climate change is the result of human activity involving many actors from the individual level (summing billions of people), to industry and governmental levels, and from national (private and public) to international institutions. To move to a LCE requires a collective action of all countries and across the entire society, from private to public sectors, from the individual to a community levels. It requires actions that go beyond legal declarations, from national legislatures and international agreement and involving national and international organizations, like the World Trade Organization and World Bank, two bodies funding research into new technologies. It also requires that these institutions coordinate and cooperate with each other to ensure that social and economic policies are not pursued in ways that destroy the environment. In many countries, the balance between private and public investment in a LCE should be driven by the market but with governmental policies and regulations that ensure the least impact on the most vulnerable communities. It is most probable that the private sector will not act on those areas where the return investment is of long-term or highly uncertain. In these cases, action from the public sector will be needed by taking responsibility on the investment or by subsidizing private ones or to the vulnerable communities. The climate change is a global problem with a global solution, even though the responsibilities are differentiated, all countries should take actions, and all industries should be involved in moving to a LCE. Today, in a global market and economy, most industrial production is also of an international scale and, therefore, they should be involved in LCE actions.

The LCE also implies the concept of low carbon technology (LCT) for energy generation and the development of new technology with zero carbon emission. This development has relationships with electricity, transportation and construction sectors; chemistry industry and many other new technologies. Globally, technology development has dramatically accelerated over recent decades in developed countries, however, this development remains slow in low- and middle-income countries. Technology transfer from developed to developing countries needs further implementation. Also, LCT involves research for improving efficiency of existing technology and for developing new technology from renewable energy that comes from natural resources. Advances in technology and policy will allow renewable energy and energy efficiency to play major roles in replacing fossil fuels, meeting global energy demand, but at the same time reducing $\mathrm{CO}_{2}$ emissions.

In summary, the world is facing a warmer environment due to human activity that has being increasing the GHG concentration. To overcome the impacts of the climate changes we need to adapt to the new scenarios, but also to reduce the GHG emission by moving to a LCE, which requires the compromise of all countries and individuals. LCE will impact the society in different way, for example on the economic growth which can be compromised; it will need a balance between private and public investment, governmental policies and regulations, research and development of new technologies. It will require an international agreement where all nations should act with generosity for the well-being of humanity.

\section{Acknowledgements}

This study was carried out when the author was still affiliated with the Dirección Meteorológica de Chile. This article is a contribution to FONDAP $\left(\mathrm{CR}^{2}\right) \mathrm{N}^{\circ} 1511009$.

\section{References}

[1] Solomon, S., Qin, D., Manning, M., Chen, Z., Marquis, M., Averyt, K.B., Tignor, M. and Miller, H.L. (2007) Contribution of Working Group I to the Fourth Assessment Report of the Intergovernmental Panel on Climate Change. IPCC 2007, Cambridge University Press, Cambridge and New York.

[2] Stocker, T.F., Qin, D., Plattner, G.-K., Alexander, L.V., Allen, S.K., Bindoff, N.L., Bréon, F.-M., Church, J.A., Cubasch, U., Emori, S., Forster, P., Friedlingstein, P., Gillett, N., Gregory, J.M., Hartmann, D.L., Jansen, E., Kirtman, B., Knutti, R., Krishna Kumar, K., Lemke, P., Marotzke, J., Masson-Delmotte, V., Meehl, G.A., Mokhov, I., Piao, S., Ramaswamy, V., Randall, D., Rhein, M., Rojas, M., Sabine, C., Shindell, D., Talley, L.D., Vaughan, D.G. and Xie, S.-P. (2013) Technical Summary. In: Stocker, T.F., Qin, D., Plattner, G.-K., Tignor, M., Allen, S.K., Boschung, J., Nauels, A., Xia, Y., Bex, V. and Midgley, P.M., Eds., Climate Change 2013: The Physical Science Basis. Contribution of Working Group I to the Fifth Assessment Report of the Intergovernmental Panel on Climate Change. Cambridge Uni- 
versity Press, Cambridge and New York, in Press.

[3] WMO (2013) The State of the Greenhouse Gases in the Atmosphere Based on Global Observations through 2012. Greenhouse Gas Bulletin, 9, 4 p.

[4] Jaeger, C.C. and Jaeger, J. (2010) Three Views of Two Degrees. European Climate Forum (ECF) Working Paper 2, Potsdam.

[5] International Energy Agency (2013) Redrawing the Energy-Climate Map. http://www.iea.org

[6] Bala, G. (2013) Digesting 400 ppm for Global Mean $\mathrm{CO}_{2}$ Concentration. Current Science, 104, 47-48.

[7] PwC (Pricewaterhouse Coopers LLP) (2012) Too Late for Two Degrees Low Carbon Economy Index. http://www.pwc.com/gx/en/sustainability/publications/low-carbon-economy-index/index.jhtml

[8] Glen, P.P., Andrew, R.M., Boden, T., Canadell, J.G., Ciais, P., Le Quere, C., Marland, G., Raupach, M.R. and Wilson, C. (2013) The Challange to Keep Global Warming below $2^{\circ} \mathrm{C}$. Nature Climate Change, 3, 4-6.

[9] Beinhocker, E. and Oppenheim, J. (2009) Economic Opportunities in a Low-Carbon World. UNFCCC E-Newsletter. https://unfccc.int/press/news_room/newsletter/guest_column/items/4608.php 